abnormal blood picture and lymphadenopathy raised the possibility of additional pathology.

The presence of marked toxic granulation in two cases and cytoplasmic vacuolation in the first case pointed to an inflammatory process and the absence of Auer rods made a diagnosis of acute myeloblastic leukaemia less likely in the first two cases. Although the bone marrow blast count in these patients was above the accepted normal range (Dacie and Lewis, 1968) this in itself does not necessarily indicate a diagnosis of leukaemia at this level and in these circumstances. The third case was altogether milder and the patient survived. Here, there was little toxic granulation, the blast count in the marrow was normal and the neutrophil alkaline phosphatase score was only just above the normal range.

It is important to bear in mind the possibility of such pronounced haematological changes in association with ulcerative colitis. Apart from the clinical picture which would usually establish the correct diagnosis, the neutrophil alkaline phosphatase score, which was elevated in all three of these patients, should be helpful where doubt exists. In addition, the experience of the second patient would suggest that fulminating ulcerative colitis should be considered in the differential diagnosis of pyrexia asso- ciated with this type of peripheral blood picture in the rare instance when these features precede gastroenterological symptoms or signs.

\section{Acknowledgments}

We wish to thank Dr J. R. Ellis and Dr G. C. Jenkins for allowing us to report these cases. Dr Jenkins was kind enough to assist in the preparation of this report.

\section{References}

Avery-Jones, F., Gummer, J.W.P. \& Lennard-Jones, J.E. (1968) Clinical Gastroenterology. Blackwell Scientific Publications: Oxford and Edinburgh.

Dacie, J.V. \& Lewis, S.M. (1968) Practical Haematology. J. \& A. Churchill, London.

Goligher, J.C., DE Dombal, F.T., Watts, J.McK., WatKINSON, G. \& MORSON, B.C. (1968) Ulcerative Colitis. Baillière, Tindall and Cassell, London.

Marsh, J.C., Boggs, D.R., Cartwright, G.E. \& Wintrobe, M.M. (1967) Neutrophil kinetics in acute infection. Journal of Clinical Investigation, 46, 1943.

MARSH, J.C. \& LeviTT, M. (1971) Neutrophilia-inducing activity in plasma of neutropenic human beings. Blood, 37, 647.

MarshaK, R.H., Korelitz, B.I., Klein, S.H., WolfF, B.S. \& JANOWITZ, H.D. (1960) Toxic dilatation of the colon in the course of ulcerative colitis. Gastroenterology, 38, 165.

Neschis, M., Siegelman, S.S. \& Parker, J.G. (1968) Diagnosis and management of the megacolon of ulcerative colitis. Gastroenterology, 55, 251.

\title{
Hodgkin's disease of the duodenum presenting with haemorrhage and perforation
}

\author{
K. D. BARDHAN \\ D.Phil., M.B.B.S., M.R.C.P.
}

\author{
Peter McArthur \\ M.B., F.R.C.S.
}

\author{
Christopher RigbY \\ M.B., F.R.C.S. \\ Royal Hospital, Sheffield
}

\begin{abstract}
Summary
A case of Hodgkin's lymphoma confined to the duodenum, draining lymph nodes and spleen, presenting with haematemesis and perforation, thus mimicking a peptic ulcer, is recorded. Such a case is not known to have been previously reported.
\end{abstract}

Correspondence: Dr K. D. Bardhan, Consultant Physician, Rotherham Hospital, Rotherham S65 DW, Yorkshire.

\section{Case report}

A 61-year-old man was admitted to hospital after suddenly developing epigastric pain followed by haematemesis and melaena. For some weeks previously he had upper abdominal discomfort and night pain, and in the week before admission had taken phenylbutazone regularly for osteoarthritis of the knees. He was obese, pale, hypotensive (blood 
pressure $80 / 60 \mathrm{mmHg}$ ) and tender in the epigastrium. It was presumed that haemorrhage had occurred from an erosion or a peptic ulcer. Following a 1500 $\mathrm{ml}$ blood transfusion he developed rigors and fever which quickly settled.

Until day 6 there was no significant change in his condition other than a mild episode of melaena. He then developed a low grade fever which began swinging up to $40^{\circ} \mathrm{C}$ on day 11 , accompanied by pain and tenderness in the right lumbar area. Appropriate investigations for subphrenic abscess and infection elsewhere were conducted but were negative. Following intramuscular penicillin and streptomycin, the fever lessened but did not stop.

An early barium meal examination was technically unsatisfactory and was, therefore, repeated on day 18. Contrast was found to leak into a large cavity of unknown nature situated in the region of the third part of the duodenum (see Fig. 1).

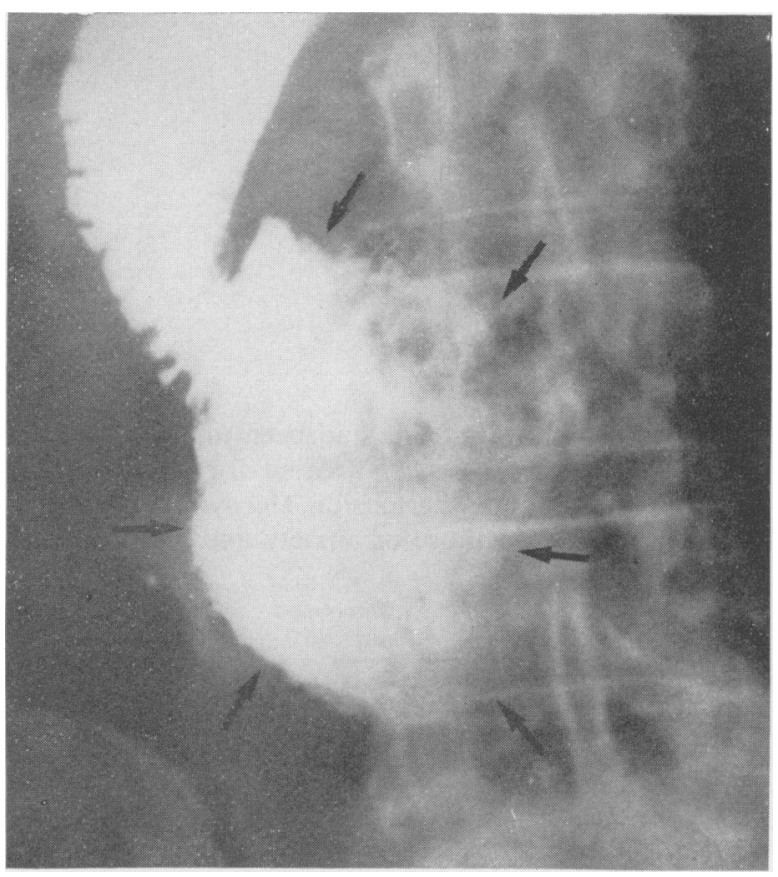

FIG. 1. Barium has leaked into a large irregular cavity in relation to the third part of the duodenum. The extent of the cavity is indicated by arrows (details in text).

Thereafter, his condition deteriorated with further haematemeses and melaena. At laparotomy on day 22 a retroperitoneal abscess cavity was found containing pus and blood clot and in communication with the third part of the duodenum through a large perforation. The perforation was repaired and a retrocolic gastroenterostomy constructed. It was considered likely that perforation was the result of malignant infiltration. Histological examination of biopsies from the pancreas and the duodenum at the margins of the perforation showed not only acute inflammation but also infiltration by a malignant lymphoma with cells characteristic of Hodgkin's disease.

He deteriorated shortly after the operation and developed high fever, pneumonia, uraemia and jaundice and died on the twenty-seventh day after admission.

At autopsy, Hodgkin's disease was found confined to the spleen $(270 \mathrm{~g})$ and to a few pancreatic lymph nodes. There was no evidence of malignancy in the walls of the abscess cavity and surrounding tissues which showed only acute inflammation.

The appearances, then, were those of Hodgkin's disease confined to a small area of the duodenum, regional lymph nodes and spleen. There was no evidence that diseased lymph nodes had eroded into the duodenum.

\section{Discussion}

The rarity of the case described is emphasized by the fact that till 1952, Portmann, Dunne and Hazard (1954) were able to find from previous publications only six cases of Hodgkin's disease involving the duodenum. Dawson, Cornes and Morson (1961), using different criteria, were convinced of only eight documented cases of primary lymphoma arising from the duodenum and, of these, there was only one case of Hodgkin's disease. More recently, Ehrlich et al. (1968) in an autopsy study of 123 cases of Hodgkin's disease found duodenal involvement in only $2 \%$. Furthermore, the mode of presentation, where described, was quite different from that encountered in this case. Indeed, a search through publications in the English language on this subject, both series and case reports, failed to reveal a similar case.

Using the rigid criteria of Dawson et al. (1961) this was not strictly a case of primary Hodgkin's disease of the duodenum, as the regional lymph nodes and spleen were involved. Nevertheless, even in cases of advanced and disseminated Hodgkin's disease, the duodenum is remarkably immune from involvement (Ehrlich et al., 1968; Balikian et al., 1969; Al-Bahrani and Bakir, 1971).

In this case, even in retrospect, the most likely diagnosis by far was haemorrhage and perforation due to peptic erosion or ulcer. The only clue to some other condition being present was the radiological demonstration of an apparent diverticulum in the region of the third part of the duodenum. A diverticulum in this area is rare, although such cases presenting with haemorrhage have been recorded (Whitmore, 1948; Pimparkar, 1964). 


\section{Acknowledgments}

We wish to thank Dr L. Henry, Consultant Pathologist, for his help and advice, the Photography Department for the illustration, Dr J. K. Barkla, Leader, Biomedical Information Project, University of Sheffield, for helping in a search of the literature aided by UK Medlars, and Mr D. $H$. Randall, Consultant Surgeon, Royal Infirmary, and Professor H. L. Duthie, Professor of Surgery, for their advice.

\section{References}

Al-Bahrani, S.R. \& BakiR, F. (1971) Primary intestinal lymphoma. A challenging problem in abdominal pain. Annals of the Royal College of Surgeons, 49, 103.

Balikian, J.P., Nassar, N.T., Shamma'a, M.H. \& Shahid, K.J. (1969) Primary lymphomas of the small intestine including the duodenum. A roentgen analysis of 29 cases. American Journal of Roentgenology, 197, 131.
Dawson, I.M.P., CoRnes, J.S. \& Morson, B.C. (1961) Primary malignant lymphoid tumours of the intestinal tract. Report of 37 cases with a study of factors influencing prognosis. British Journal of Surgery, 49, 80.

Ehrlich, A.N., Stalder, G., Geller, W. \& Sherlock, P. (1968) Gastrointestinal manifestations of malignant lymphoma. Gastroenterology, 54, 1115.

Pimparkar, B.D. (1964) Gastroenterology (Ed. by Henry L. Bockus), Volume II, p. 138. W. B. Saunders and Company: Philadelphia and London.

Portmann, U.V., Dunne, E.F. \& Hazard, J.B. (1954) Manifestations of Hodgkin's disease of the gastrointestinal tract. American Journal of Roentgenology, Radiotherapy and Nuclear Medicine, 72, 772.

WhitMORE, W.H. (1948) Duodenal diverticula with ulceration. American Journal of Roentgenology, Radiotherapy and Nuclear Medicine, 59, 343.

\title{
Thioridazine-induced diarrhoea
}

\author{
A. B. S. Mitchell \\ M.B., M.R.C.P. \\ Department of Gastroenterology, Charing Cross Hospital, London
}

\section{Summary}

Treatment for hypertension in a 68-year-old woman led to anxiety and depression which, in their turn, were successfully treated with thioridazine. Subsequent diarrhoea was shown to have been a side effect of this tranquillizer.

\section{Introduction}

Drugs based on the phenothiazine nucleus are frequently used for their psychotropic effects. Constipation is a common unwanted effect on bowel function (Kinross-Wright, 1955; Lomas, Boardman and Markowe, 1955; Hollister, 1961; Martindale, The Extra Pharmacopoeia, 1972; Shepard, Lader and Lader, 1972). Diarrhoea is mentioned in Martindale, The Extra Pharmacopoeia (1972) as an occasional complication of such therapy, but no references are cited, and the cases reported by Grahmann (1967) had complex additional symptomatology.

Diarrhoea has not previously been reported as a complication of thioridazine ('Melleril') therapy. In the following case this coincidence was such as to suggest a causal relationship.

Correspondence: Dr A. B. S. Mitchell, Consultant Physician, Prince of Wales Hospital, London N15 4AN.

\section{Case report}

A 68-year-old housewife had been under medical care for 6 years and been treated for labile, predominantly systolic hypertension. Her symptoms during this time were those of anxiety and depression,

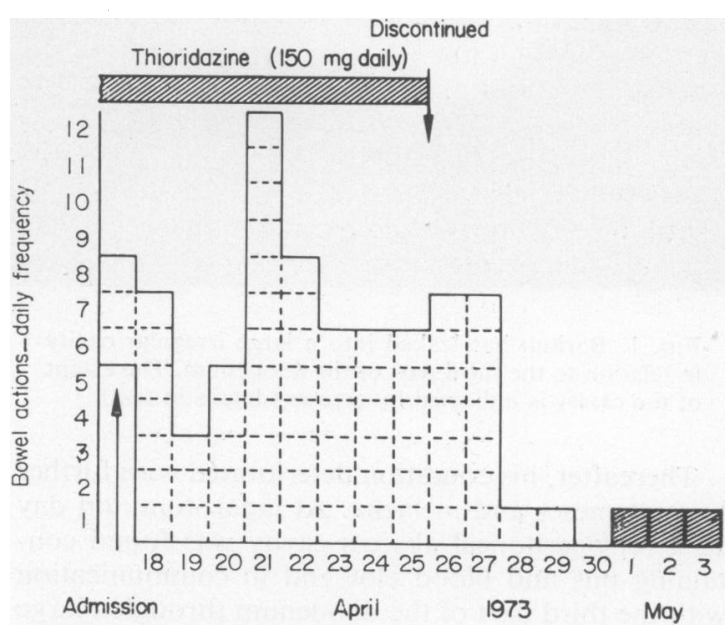

Fig. 1. Frequency and consistency of bowel actions related to drug exposure. Liquid, $\square$; formed, 